\title{
DYSFUNCTIONAL SEMANTIC ROLE OF LANGUAGE IN LITERARY TEXTS: A CASE STUDY ON HAROLD PINTER'S MOUNTAIN LANGUAGE
}

\author{
Yadgar Faeq Saeed ${ }^{1}$, Areen Ahmed Muhammed ${ }^{2}$ \\ 1, 2 English Department, Charmo University, College of Education and Languages, \\ Chamchamal, Kurdistan Region, Iraq \\ E-mail: areen.muhammed@charmouniversity.org
}

Received: 14 November 2019

Accepted: 16 December 2019

\begin{abstract}
Language and literature are two inseparable subjects, one of which cannot be fully functional with the absence of the second part. This article shows the dysfunction of semantics in Harold Pinter's Mountain Language. For many years, scholars and linguists work separately on different cases regarding literary texts or linguistics obstacles. From this paper, a new path will be saved for future references and works to bring both cases together and show their roles on one another. Moreover, literary works pay less attention to grammatical rules and plenty of dysfunctional languages can be examined and seen. In addition, several external factors can be the obstacle of using functional and accurate language use semantically and systematically. Moreover, political or social violence have become major points in many literary topics in the modern era. This study deals with theoretical aspects of society starting from family up to community and government. Additionally, the absence of semantics in the language of this drama is not neglected arbitrarily; whilst, there is a loop of violence. There are some basic theories related to the topic that this paper will examine. It includes the theory of Grice's maxims (Gricean maxims) and the role of semantics when it comes to politics and power. Finally, the paper alienates all the curtains and shows the role of power, gender differences, class status, and diversity on language use in many areas.
\end{abstract}

Keywords: dysfunction of language, semantic role, language acquisition, maxims of Grice, cooperative principle, and gender divisions.

\section{Introduction}

Language is considered as the significant way of communication and it is regarded as the crucial factor in any society or culture. Moreover, it is the mirror of any ethnic group since communication in the used language will show the history and identity of that nation. On the other hand, literature served any community with the richness of language vocabularies and structures. The grammatical and semantic dysfunction of language can be seen in many modern literary works, not only in Pinter's Mountain Language but also in Samuel Beckett's Waiting for Godot. In Waiting for Godot, Beckett devaluates language from the beginning until the end. In it, the characters are using a language, which does not function at all. However, unfortunately, only very few studies can be found in the subject area. Moreover, the role of language under the effect of power, politics, religion, gender differences, and 
Dysfunctional Semantic Role of Language in Literary Texts: A Case Study on Pinter's Mountain Language, Yadgar Faeq Saeed, Dr Areen Ahmed Muhammed

society will be obfuscated in the sectors of voice and tone, syntactic structure, semantic meaning, and style. In addition, Collins (2006) describes the role of language use in daily communication and its absence in literary texts. He refers back the problem to different external factors, which all are related to cultural identity. In another source, Hooks (2000) warns language users regarding the effects of social class divisions on language use. Further references can be found in the works of both Kubota (2003: 38) and Luke (2010). Kubota states that languages "need to be unpacked in relation to power and discourse". While according to Luke and Vandrick (2014), "class intersects and interacts with other identities, such as race, gender, ethnicity, religion, and sexual identity".

In this article, the researchers not only examine the dysfunction of language in Pinter's Mountain Language but also apply the conversational maxims. Grice (1975) states that human beings need to make their contribution [speech] such as required and Grice tends, in his Gricean maxims, Quality - Quantity - Relation and Manner; he studies the people's behaviour during conversation. This article applies the different types of Cooperative Principles on Harold Pinter's play.

To the great extent, external factors such as gender differences, class priority, political parties, etc. will affect not only the degree of politeness and formality in a language but also the linguistic typology and linguistic variations. It is the common sense that English is the language that often advocates for social justice and usually focuses on learners' identities, races, genders, and ethnicities; however, less opportunity is given to social class identification. Yet, social class plays an important role in language use. Especially, in many literary works, the language is used while it is dysfunctional. Because of the current issue, the paper will focus on Pinter's play, Mountain Language to analyze the factors that may cause the dysfunction of semantic use of language.

Pinter's Mountain Language is the type of play where the suppression of language is palpable. Pinter's use of dramatic techniques in the play is unique in that it not only conveys the sense of suppression against the characters but also shows how the regime and the ruling system can "kill" a specific language and call it "dead" and prevent the people from using their own native language. Although there are many clues about the fact that Pinter's purpose in writing his "Mountain Language" was shedding on the condition of the Kurdish people in Turkey and how the Turkish regime banned their language, Pinter himself never gave his readers a clue about this and in some occasions, he even denied it. Knowing that in 1985, Pinter visited Turkey with fellow playwright, Arthur Miller, and Mountain Language is written after three years from their visit to Turkey, but the large-scale generalization of Pinter's literary productions makes his style a unique and universal one.

\section{Literature Review}

\subsection{Harold Pinter: The Literary Background}

Harold Pinter (1930-2008) was a British playwright, screen and scriptwriter, director, and actor; he is considered as one of the most considerable and well-known modern writers. In addition, Pinter was a veteran who lived and experienced two different centuries and his writing career spanned over fifty years. Moreover, Pinter's Jewish heritage caused him many problems, the suppression of mother tongue started with him in his early childhood, and this suppression grows with Pinter.

In an article dated back to November 5, 1989 "Peter Nicholas" wrote a review about Mountain Language and published it in The New York Times under the title "THEATER; Even the Language is Taken Away". Nicholas states Harold Pinter's "point of view" about 
Mountain Language. "The play is about suppression of language and the loss of freedom of expression," from Pinter's own point of view one can decide that the playwright wanted to highlight a situation, which he experienced; this was a crystal-clear shift from his style in which Pinter's work turned to the cause of human rights.

According to encyclopedia.com, Mountain Language opened at the National Theatre in London on October 20,1988, directed by Pinter himself. The play belongs to the Theatre of the Absurd, and most of the characteristics of Absurdism can be found in it, for instance, alienation, nostalgia, dysfunctional language, meaninglessness, censorship, sexual abuse, resistance, collapse of morality, and disillusionment.

\subsection{Dramatic Analysis of Mountain Language}

Pinter's Mountain Language is a one-act play and consists of four short scenes. The setting is in front of and within a police state, where all the events take place. In the first act, a line of women who want to visit their imprisoned husbands are standing at a prison wall. They have been standing there from 9:00 AM to 5:00 PM in the snow, as a character states; a sergeant and an officer question them ... A dog has bitten one of the women. The officer tells the women that their language, namely that of the mountain people, is forbidden and that their husbands are enemies of the state, that is why they are not allowed to speak their "mountain" language and need to speak the capital's language.

In the ceremony of the Nobel Prize in Literature 2005, Harold Pinter, who won the prize, asserts, "Mountain Language [...] remains brutal, short, and ugly. However, the soldiers in the play do get some fun out of it. One sometimes forgets that torturers become easily bored. They need a bit of laugh to keep their spirits up."

Pinter was aware when he used only four short acts or scenes to portray the oppression of language by the dictator regimes; what he wants to show the reader is what happens when the political system prevents you from using your own mother tongue. That is why he says that his play is a short one but ugly at the same time; short because it depicts a small period of the life of his characters yet ugly in a way that the audience cannot stand the scene.

When one examines the dramatic structure of Pinter's Mountain Language and Beckett's Waiting for Godot, many similarities can be found. In addition, Vivian Mercier wrote in the Irish Times in 1956 that Samuel Beckett had "written a play in which nothing happens, twice". Mountain Language is also that type of play in which nothing happens twice and all the events take place in a way that the audience feels disappointed. The cause and the only thing that the audience is aware of is that those people are considered to be the enemies of the state without declaring why! Pinter's Mountain Language is an absurd play, and like most of the absurdist writers, this literary production of Pinter annoyed many of its readers and spectators at the same time; in his Poetics (335 BC), Aristotle clarifies his unities for a tragic worker of art AKA Classical Unities or Aristotelian Unities, namely: (1) Unity of Action: a tragedy should have one principal action, (2) Unity of Time: the action in tragedy should occur over a period of no more than 24 hours, (3) Unity of Place: a tragedy should exist in a single physical location.

Speaking about Pinter's Mountain Language, we can say that Pinter, intentionally, applied and followed all the three unities but at the same time, he used them just to violate and flout them. Although there is only one action, 24 hours and a single location, Pinter never explained the exact setting of the events. Maybe, he wanted to add a touch on universality to his play, so, everyone can relate it to his/her personal sufferings, anywhere 
Dysfunctional Semantic Role of Language in Literary Texts: A Case Study on Pinter's Mountain Language, Yadgar Faeq Saeed, Dr Areen Ahmed Muhammed

and at any time. Regarding Pinter's inspiration while writing Mountain Language, a study guide for Harold Pinter's Mountain Language by experts from Gale, Cengage Learning, affirms that Pinter's inspiration to write his play came from "the long history of oppression the Kurds suffered under the Turkish rule." In order to have a universal appeal, Pinter's plot centres around a prison guarded by "unnamed guards" in an "unnamed country" and the charges against the prisoners are "unnamed" too. Moreover, another clear clue that the playwright addresses the Kurds and their case is the use of "forbidden language" by the state representatives in the play, which fortifies the condition of the Kurd in Turkey. Meanwhile, different Turkish governments prevented the Kurds from speaking and using their own language and many Turkish politicians used the term "mountain people" or "mountain Turks" for the Kurds (Bartkus, 1999: 91-92).

Another interpretation of Mountain Language portrays the play to be Pinter's attempt to convey a message about human rights condition in some places of the world. The Universal Declaration of Human Rights in Article 19, states: "Everyone has the right to have freedom of opinion and expression; this right includes freedom to hold opinions without interference and to seek, receive, and impart information and ideas through any media and regardless of frontiers."

While, Pinter ironically attacks the totalitarian world leaders by stating that the relatives of the prisoners do not have the right to speak their own native language, while freedom of speech and freedom of the language that you speak are considered to be the most basic human rights as seen in the following quotes:

OFFICER: Now hear this. You are the mountain people. You hear me? Your language is dead. It is forbidden. It is not permitted to speak your language in this place. You cannot speak your language to your men. It is not permitted. Do you understand? You may not speak it. It is outlawed. You may only speak the language of the capital. That is the only language permitted in this place. You will be badly punished if you attempt to speak your mountain language in this place. This is a military decree. It is the law. Your language is forbidden. It is dead. No one is allowed to speak your language. Your language no longer exists. Any questions? (21)

It is ironic that the same person who tells them that their language is dead, forbidden yet threatens them not to speak it; on the other hand, he wants to know whether they have any questions. In addition to all the clear characteristics of modernism and Theatre of the Absurd, one can find a nostalgic tone and atmosphere in the play, as if the characters are trying to escape the "now" that they are in and live in a past that seems impossible and unreachable for their present time:

MAN'S VOICE: I watch you sleep. And then your eyes open. You look up at me and smile.

WOMAN'S VOICE: You smile. When my eyes open I see you above me and smile.

MAN'S VOICE: We are out on a lake.

WOMAN'S VOICE: It is spring.

MAN'S VOICE: I hold you. I warm you.

Gill in his Mastering English Literature (2006: 224) writes, "Tragedy makes us engage with the problems of human morality." Depending on this claim, one can say that "Mountain Language's" genre falls under tragedy, as Pinter wanted to highlight a problem that is considered a crisis in the field of human rights until the present time. However, when the 
audiences check the play in hope of finding a hero or a heroine then they fail; maybe, Harold Pinter wanted to tell us that the hero of his play is not a person but a "nation".

\subsection{Cooperative Principles of Language}

Human beings are social creatures and one of the ways that they communicate is using words, i.e., language; every communication through a language needs a speaker and a listener, it is through this they will understand each other and share same or different feelings. H. P. Grice (1975) in an article under the title "Logic and Conversation" introduces his four maxims (Quality, Quantity, Relation, and Manner). Paul Grice (1975) also invented a principle of conversation and the levels of communication called 'Cooperative Principle' asserting that effective communication between people needs some principles of conversation from both speaker and listener's side, these principles were later called Gricean Maxims. These principles are considered to be a method of understanding the meaning of dialogues and conversations that people make and interpret the intentions of the utterances and why specific characters observe or flout specific maxim(s).

Harold Pinter's Mountain Language is one of the universal plays in which language becomes dysfunctional and the characters do not seem to hear or listen to each other's words. As the researchers mentioned before, the modern man does not seem to care about other's contribution and the only thing he is doing is simply speaking without caring about the answers or what they have been asked. Grice's theory of maxims (1975) is a guide, which can be used to explain and comment on the Pinter's intentions in writing his Mountain Language (1988).

The Cooperative Principle (CP) is a conversational principle developed by Herbert Paul Grice, a British philosopher of language in 1975. He asserts, "Participants expect that each will make a conversational contribution as required, at the stage at which it occurs, by the accepted purpose or direction of the talk exchange" (Grice, 1975: 45). This means that the cooperative principle accounts for conversational implicatures, something the speaker implies with an utterance, even though it is not literally expressed. Participants of the conversation assume that a speaker is being cooperative, and they make conversational implicatures about what is said (Levinson, 1983: 101) and (Crystal, 1985: 153).

Grice says that speakers want to be cooperative while talking and they want to be as cooperative as possible. Being cooperative means the speaker knows that each utterance from his/her side is an intervention in the privacy, personal space, autonomy, and demands of the other. That is the reason why we have to select and think about our utterances in a way that is as precise and suitable as possible to the context (Bach, 2003). Grice invented the principles of cooperation to describe a conversation. He stated, "make your conversational contribution as required, at the stage at which it occurs, by the accepted purpose or direction of the talk exchange in which you are engaged" (Grice, 1975:183). Grice's Cooperative Principle is a set of measures that can be noticed in conversations. They are four maxims; observing this set of maxims will result in being cooperative and understood at the same time:

1. Maxim of Quality: Under the category of Quality falls a super-maxim- try to make your contribution one that is true- and two more maxims that are specific:

a. Do not say what you believe to be false.

b. Do not say that for which you lack adequate evidence. 
Dysfunctional Semantic Role of Language in Literary Texts: A Case Study on Pinter's Mountain Language, Yadgar Faeq Saeed, Dr Areen Ahmed Muhammed

2. Maxim of Quantity: Paul Grice clarifies that the category of Quantity relates to the quantity of information to be provided, and under it fall the following maxims:

a. Make your contribution as informative as is required (for the current purposes of the exchange).

b. Do not make your contribution more informative than is required (Grice, 1975: 308).

3. Maxim of Relation: The response has to be relevant to the topic of discussion.

4. Maxim of Manner: The speaker has to avoid ambiguity or obscurity; s/he should be direct and straightforward (Bach, 2003).

The cooperative principle assumes that in conversation analysis the participants try to be truthful (Quality), informative (Quantity), relevant (Relation), and clear (Manner). Grice, the founder of the four principles, argues, "Talk exchanges are not merely a succession of disconnected remarks, and would not be rational if they did. They are characteristics, to some degree at least, cooperative efforts and each participant recognizes in them to some extent a common purpose or set of purposes or at least a mutually accepted direction" (Grice, 1975: 184) and (Nordquist, 2019). Grice suggests that in every dialogue the participants have a particular and/or a fixed intention; they start to converse in the hope of finding an answer for their inquiries and questions. Moreover, Birner in her Introduction to Pragmatics writes about the four ways of the speaker's behaviour when it comes to $\mathrm{CP}$, he or he can: observe the maxims, violate the maxims, flout the maxims, or opt-out the maxims (Birner, 2013: 43).

To observe a specific maxim means to implement it, i.e., to say the right amount of the words when someone asks a question. Moreover, observing is saying what you believe to be right and you have an adequate proof for it, and it must be relevant to the question and, of course, accurate, understandable, monosemous and unambiguous (depending on the type of the maxim in the asked question). Violating a maxim takes place when the speaker fails to observe it. Violating a maxim is not similar to flouting it; the speaker makes a statement and they are aware that it is false or not true (non-observance of Maxim of Quality). Flouting out of a maxim takes place after violating it, but in this case, the violation is transparent and unmistakable in a way that the hearer is aware and notices the flouting out. To opt-out a maxim is when the hearer is not a part of the conversation anymore and refuses to contribute, for example, "a friend wants to ask for my consultation in a problem that I already warned him about, then I neglect him and read a book instead, I decided to opt-out" (Birner, 2013: 43).

\subsection{The Absence of Grice's Maxims from Linguistic Perspectives: Mountain Language}

In order to understand Mountain Language one needs to know Harold Pinter in the first place, Raby in The Cambridge Companion to Harold Pinter mentions a letter that Pinter has sent to President G. W. Bush, the 43rd president of the United States, from 2001 to 2009 (2009: 105):

Dear President Bush, I am sure you will be having a nice little tea party with your fellow war criminal, Tony Blair. Please wash the cucumber sandwiches down with a glass of blood. (Harold Pinter, the Guardian, 18 November 2003) 
Surprisingly, two years after composing the above letter Harold Pinter was awarded the Nobel Prize for Literature. Pinter's writing style on the topics he has tackled shifted to politics and freedom of expression after the 1980s, starting with Mountain Language until we reach his late years. Pinter did his best to be the voice of the suppressed nations worldwide, knowing that he never confessed whom he means by "mountain language" people. However, one can always relate it to different nations worldwide. Although the most apparent case in the Middle East is the Kurd's question in Turkey, Pinter himself wrote a piece of article as a tribute to his friend, Arthur Miller, on his $80^{\text {th }}$ birthday under the title "Campaigning against Torture":

Arthur Miller and I landed at Istanbul airport on March 17, 1985. We were

visiting Turkey on behalf of International P.E.N., to investigate allegations

of the torture and persecution of Turkish writers.

Pinter and Miller visited Turkey in 1985 and Mountain Language was published in 1988, surprisingly the same year that Saddam Hussein's regime performed eight campaigns of Anfal and used the chemical weapon in Iraqi Kurdistan's Halabja region, which resulted in killing of more than 190 thousand in Kurdistan Region of Iraq according to Human Rights Watch's report (1993).

\subsubsection{Gricean Maxims in Mountain Language}

In the previous sections, we explained many things related to Mountain Language and the different situations that may encourage Pinter to jot down his masterpiece, now, the researchers will provide some of the places in the play where the CPs were violated, flouted, or opted out.

Example One:

SERGEANT: Name?

YOUNG WOMAN: We've given our names.

SERGEANT: Name?

YOUNG WOMAN: We've given our names.

OFFICER: [To Sergeant] Stop this shit. (1)

In this example, the speaker and his opponent are not arguing over a topic, which will lead to mutual understanding. As a result, the violation of Maxim of Quantity takes place because the hearer refuses to reply to the question and provide information on one hand, and on the other hand, the hearer opts out the maxims of Quantity and Relation when the Young Woman's answer is vague. At the same time, the Officer violates the maxims of Quantity, Relation, and Manner when he describes the Sergeant's speech as "shit".

\section{Example Two:}

In this scene, the Young Woman wants to inform the state men how the Elderly Woman has been beaten, seeking attention, and some contribution, but the Sergeant opts out and moves away from answering, thus he violates, flouts, and opts out the maxims of Quality and Relation, instead asks, "What is your name?" Therefore, when the Young Woman does not give her name, the officer degrades and offends her and asks for the name of the dog that has beaten her:

What was his name? (Pause) What was his name? (Pause) Every dog has a name! They answer their name. They are given a name by their parents and that is their name.... (3). 
Dysfunctional Semantic Role of Language in Literary Texts: A Case Study on Pinter's Mountain Language, Yadgar Faeq Saeed, Dr Areen Ahmed Muhammed

\section{Example Three:}

OFFICER: Now hear this. You are the mountain people. You hear me? Your language is dead. It is forbidden. It is not permitted to speak your language in this place. You cannot speak your language to your men. It is not permitted. Do you understand? You may not speak it. It is outlawed. You may only speak the language of the capital. That is the only language permitted in this place. You will be badly punished if you attempt to speak your mountain language in this place. This is a military decree. It is the law. Your language is forbidden. It is dead. No one is allowed to speak your language. Your language no longer exists. Any questions?

This quotation is considered to be the core of what Pinter wanted to share with his audiences; it is obvious from the title Mountain Language that the playwright speaks about a specific type of language which is used by the 'mountain people'. In the previous sections, the researchers stated "Participants expect that each will make a conversational contribution as required, at the stage at which it occurs, by the accepted purpose or direction of the talk exchange" (Grice, 1975: 45). When this occurs all the maxims are observed; but looking at the above speech and the highly repetitive speech of the officer is far away from observing the maxims. By looking at the context of this dialogue, one understands that the officer's statements are paradoxical because he insists that his opponent character should know that their language is forbidden yet he continues asking them if they have any questions or complaints about it. Last but not least, in here, the speaker violates the maxim of Quantity by uttering more than required and flouts the maxim of Manner too because it is not still clear for the audiences why the visitor's language is forbidden.

There are many other different places and occasions in Pinter's Mountain Language, where the characters are violating, flouting and opting out the Gricean maxims for different reasons. In one of the scenes the state man tries to sexually abuse the woman in front of the public, this, too, is considered as one of the places of language dysfunctions, where violation of human rights and harassment take place.

\section{Result and Discussion}

\subsection{The Position of Class, Violence, and Gender Divisions in Language Dysfunction}

According to the source by Al Sweidi and Al Azraki (2011), the word violence is taken from the Latin word of (Vis) (force) and (latus) (to carry). Etymologically speaking, the word (violation) comes from the same source of (violence). Linguistically, the outer force may affect the role of language use according to class divisions and the position of class, and gender differences can violate linguistic rules when a language in a specific pattern is used. It is in Gale's idea "which suggests to us the interesting idea that somehow a violation of something: that carrying a force against something constitutes, in one way or another, violation of it" (Galer, 1986: 59). Furthermore, among different genders clear cut violence can be seen during language use not only through suppressing power, but also through the priority of voice for males on females, as it can be seen in the case of "Mountain Language" when the female prisoner is bullied linguistically and her language is dysfunctional since she is female gender. Additionally, she is from the low class, as the officer calls her "mountaineers" (Galer, Ibid, and Viri, 1988).

Apparently, psychologists, sociologists, and linguists try to stop such attitude in the sense of language in literary texts to bring back the moral elements and functionality of the 
language in the aspect of semantics; in their paper, Al Sweidi and Al Azraki (2011), Gronow, and Hilppo (1970), they discuss the issue of language violation due to social status. While according to Derriennic (1972) language will be dysfunctional indirectly when there is a psychological violence, especially in the case of gender violation; this intentionally will mislead the listener and will be regarded as inequality of power distribution on language use. In addition, the art of language will disappear due to the above-mentioned factors (Singh, 1976).

In addition, Quigley (1975) states that language is important to the point when there is equality; however, that role will disappear or blur when the external factors have power on personal use of language. According to him, Pinter is selecting silence to communicate and describe that tyranny in Mountain Language. Moreover, Kane (1984) and Perkins (2002) state that Pinter's silence is not due to dumbness or misunderstandings, while the silence is a metaphor for isolation and inequality. Most of the plays by Harold show language dysfunction, since the position of class and gender division play crucial roles during the time of the language use. In addition, the rulers of power rather than syntactic variations dominate the language. According to many linguists, the language, which is used in Pinter's texts, is considered as linguistic genocide, since the female genders are forced to stop speaking in their native and mother tongue. However, they are forced to use the capital language that is more functional. In addition, the languages apart from those with the highclass division are considered as the dead language in most of the literary texts. (Pinter, 2006)

Gender discrimination and differences are counted as another main factor when a language is used. The role of female gender will be degraded more than males; also, levels of education, position and status, class divisions, and male dominancy will cause gender differences in language use and speech style. Though many linguists for decades talk about the gender differences in the case of language use; however, it was as early as the 70s when social roots of these differences were appointed. Furthermore, the more distinct the roles are, the greater the gap can be seen. Largely, most of the important positions in government are given to a male, and this created male dominancy (Morgan, 1968). For Lakoff (1975) language is a kind of cultural phenomenon, as the use of language will be dysfunction when each of class status and violence appear.

\subsection{The Effect of Political Power on Semantic Use of Language}

The common play, undoubtedly, is regarded as violence in a political situation. The speeches that were said by the prisoners and outsiders were disqualified since they could not reach the level of the politicians in the drama. Due to the fact, the speech and complaints were keeping interrupted by other trivial excuses such as "tell us the name of the dog" or "whose dog was that" (Trussler, 1985). In addition, the female prisoner's words were counted as useless and her language was not counted as the usable one since she was not from the same political party as the officers and sergeants were. Additionally, Odegard (1956) mentions that the ruling class (mayors, officers, or politicians) use their political power to stop the use of the language which is used by the lower class; then their (lower class) language will be with no use or function neither semantically nor syntactically. Similarly, the same case can be found in the current play, since the prisoner is stopped from complaining because she is using a mountain language and politically it is forbidden. A quote by Trussler (1985: 87-88) will depict the idea and he describes the role of political suppression on language use through centuries; he says: 
The springboard...was the Kurds, but this play is not about the Turks and the Kurds. I mean, throughout history, many languages have been banned-the Irish have suffered, The Welsh have suffered, and Urdu and the Estonians' language banned....My own view is that the present government [British] is turning a stronger voice on democratic institutions that we've taken for granted for a very long time.

The political party of the dominant language dominates minority languages. It is no longer self-possessed and cannot be recognized fully under capital rules due to the geographical status of the used language. Moreover, the clash of identity and civilization may affect the linguistic rules of the nation; hence, many languages around the world cannot be used due to the religious or political issues like in the case of Mountain Language. Additionally, the political violence affected the role of using language freely such as Irish and Basque which suffered from such tyranny in the past (Conversi, 1997; Kockel, 1999; and NicCraith 2006).

Marginalization and the manifestation of social classes and political power affect the linguistic factors of any language (Block, 2012a, 2012b, and, 2014), (Ramanathan and Morgan, 2009). In addition, Lin (1999) urges linguists and scholars of language to raise awareness through papers so that the role of politics could be less influential on linguistics and semantic use of language. As he says, "rules lay down by the privileged classes" (Ibid, 411). Due to the poverty and role of political violence, minorities are struggling by using the native language or even in the time of use; contextually it will not be counted as primitive language (Nader, 1972). In addition, "there is comparatively little field research on the middle class and very little firsthand work on the upper classes ... what if . . . anthropologists were to study the colonizers rather than the colonized, the culture of power rather than the culture of the powerless, the culture of affluence rather than the culture of poverty?" (Ibid, 289) the questions are still uncovered until the current time.

\section{Conclusion}

Different writers depict different issues for discussion and further studies; in the case of the common play by Harold Pinter. The topic on the dysfunction of language is selected since semantically the language inside the play carries no power and the one with higher political power or class can select the language of communication. Moreover, each writer deals with different factors of language differently; however, in most cases of modern writers of literary texts, language rules are neglected intentionally for different reasons. For Pinter, the idea of "violence" carries the full meaning of language; in other words, the authority has the power to shift the language and disqualify the second language. It shows that political power, social status, male dominancy, etc. can manipulate the language use and degrade the spoken or written language of the ethnic group, which is less powerful politically or even socially. Pinter's work is regarded as two parts of communicators: a linguistic unit and a language unit. He proved that the dominant language is the one with more power. In addition, in the current paper, a clear cut difference can be found in the language use of characters; basically, the play is related to many minority ethnic groups by which due to the power of politics, society, class division, and gender differences on them their language is turned to dysfunction.

The social class factors are not only an abstract topic but also strengthen the language boundaries, as it will affect the functionality of the language. In the current paper, different factors were mentioned; whilst, the most effective ones are violence, political parties, class 
divisions, and gender differences. Additionally, the maxims of Grice and different cooperative principles were described to illustrate the play from both linguistic and literary perspectives. In the early sections of the paper the works and dramatic analysis of the Pinter's Mountain Language is explained. It is recommended that further studies and investigations should be carried out to show the dysfunction of language use in many literary texts and especially modern plays. Additionally, this will raise awareness among students of English department to know the importance of both literature and linguistics during their lifetime. Since those two fields are tightly interrelated.

Finally, in the course of the paper the researchers concluded that there is a huge similarity between the works of the modern playwrights; especially the works that belong to Theatre of the Absurd; due to the WWI and WWII. The measures that we can use while measuring the levels of contribution from both the speaker and hearer's sides, one finds that in most of the cases they do not observe, violate and/or opt-out the Quality, Quantity, Relation and Manner when they speak. Moreover, this works function as a clear clue and proof that the function of language changed from one that works and is productive to something that cannot help the contributors; in other words, language becomes futile just like the human beings of the modern age.

\section{References}

Al-Sweidi, I., and Al-Azraki, A. (2011). The politics of violence in John Arden's and Harold Pinter's selected plays. Journal of Basic Education, 1, 69-86.

Bach, K. (2003). Speech acts and pragmatics. Routledge Encyclopedia of Philosophy. Retrieved from: http://userwww.sfsu.edu/kbach/Spch.Prag.htm

Bartkus, Viva Ona. (1999). The dynamic of secession. London UK: Cambridge University Press. Birner, Betty, J. (2013). Introduction to pragmatics. Wiley-Blackwell, UK: Library of Congress.

Block, D. (2012a). Class and SLA: Making connections. Language Teaching Research, 16(2), 188-205.

Block, D. (2012b). Economizing globalization and identity in applied linguistics in Neoliberal Times. In D. Block, J. Gray, \& M. Holborow (Eds.), Neo-liberalism and applied linguistics (pp. 56-85). New York, NY: Routledge.

Block, D. (2014). Social class in applied linguistics. New York, NY: Routledge.

Conversi, D. (1997). The Basques, the Catalans, and Spain: Alternative routes to nationalist mobilization. London: Hurst.

Crystal, D. (1985). A dictionary of linguistics and phonetics. New York: Basil Blackwell.

Derriennic, J. (1972). Theory and ideologies of violence. Journal of peace research, 9(4), 6572.

Galer, H. (1986). Violence in perspective. Oxford: Oxford UP.

Gill, Richard. (2006). Mastering English literature (third Ed.). Palgrave Master Series.

Grice, H. P. (1975). Logic and conversation. In P. Cole, \& J. Morgan, Studies in syntax and semantics III: Speech acts (pp. 183-198). New York: Academic Press.

Hooks, B. (2000). Where we stand: Class matters. New York, NY: Routledge.

Human Rights Watch. (1993). Genocide in Iraq: The Anfal campaign against the Kurds.' Retrieved from http://www.hrw.org/legacy/english/docs/2006/08/14/iraq13979 txt.htm

Kockel, U. (1999). Borderline cases: The ethnic frontiers of European integration. Liverpool UK: Liverpool University Press. 
Dysfunctional Semantic Role of Language in Literary Texts: A Case Study on Pinter's Mountain Language, Yadgar Faeq Saeed, Dr Areen Ahmed Muhammed

Kubota, R. (2003). New approaches to gender, class, and race in second language writing. Journal of Second Language Writing, 12(1), 31-47.

Lakoff, R. (1975). Language and women's place. New York US: Harper \& Row Publishers, Inc.

Lin, A. M. Y. (1999). Doing-English-lessons in the reproduction or transformation of social worlds? TESOL Quarterly, 33(3), 393-412.

Luke, A. (2010). Documenting reproduction and inequality: Revisiting Jean Anyon's social class and school knowledge. Curriculum inquiry, 40(1), 167-182.

Morgan, R. (1968). Going too Far: The personal chronicle of a feminist. New York USA: Random House.

NicCraith, M. (2006). Europe and the politics of language: Citizens, migrants, outsiders. Basingstoke, New York NY: Macmillan/Palgrave.

Nordquist, R. (2019). The cooperative principle in conversation. (2019, January 11). Retrieved from: https://www.thoughtco.com/cooperative-principle-conversation 1689928

Pinter, Harold. (2006). The essential Pinter. London UK: Grove Press.

Pinter, Harold. (2019). Nobel lecture. Nobel Prize.org. Nobel Media AB 2019. Nov 2019. Retrieved from: https://www.nobelprize.org/prizes/literature/2005/pinter/ 25621harold-pinter-nobel lecture-2005/

Pinter, Harold. (2001). Mountain Language. London UK: Faber and Faber.

Quigley, A. E. (1975). The Pinter problem. Princeton N.J: Princeton University Press.

Raby, Peter. (2009).The Cambridge companion to Harold Pinter (second Ed.). London UK: CUP.

Ramanathan, V., \& Morgan, B. (2009). Global warning? West-based TESOL, class blindness, and the challenge for critical pedagogies. In F. Sharifian (Ed.), English as an international language: Perspectives and pedagogical issues (pp.153-168). Clevedon, UK: Multilingual Matters.

Singh, G. (1976). Politics and violence. Social scientist, 4(11), 110-119.

Trussler, S. and Arden, Ed. (1985). On File. London UK: Methuen.

Vandrick, S. (2014). The role of social class in English language education. Journal of language, identity, and education, 13(2), 85-91.

Viri, W. (1988). Violence and law: Essays on violence. New York USA: Grove Press. 